\title{
Las minorías socio-religiosas hispanas en los manuales escolares de enseñanzas medias en España (1970-2018) ${ }^{1}$
}

\author{
Hispanic Socio-Religious Minorities in Secondary School Textbooks in Spain (1970-2018) ${ }^{2}$
}

\section{As minorias sócio-religiosas hispânicas nos manuais escolares do ensino fundamental em Espanha (1970-2018) ${ }^{3}$}

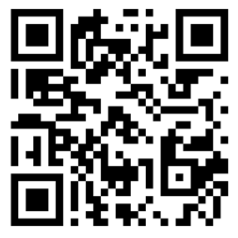

\author{
Francisco Javier Moreno-Díaz del Campo \\ Universidad de Castilla-La Mancha \\ Ciudad Real, España \\ franciscoj.moreno@uclm.es \\ https://orcid.org/0000-0001-7929-5080
}

Recibido • Received • Recebido: 25 / 10 / 2019

Corregido • Revised • Revisado: 27 / 06 / 2021

Aceptado • Accepted • Aprovado: 25 / 08 / 2021

\begin{abstract}
Resumen:
Introducción. Las sociedades occidentales se enfrentan al reto de desarrollar metodologías docentes que apuesten por la integración de las minorías y la atención a la diversidad de un alumnado cada vez más heterogéneo. La historia puede contribuir a dicha misión, especialmente cuando estudia el pasado de grupos que fueron perseguidos por su origen, ideas o creencias. Metodología. Este artículo analiza cuáles han sido las narrativas y metodologías empleadas en el último medio siglo en las aulas de enseñanza secundaria españolas para analizar la historia de personas judeoconversas y moriscas, las dos principales minorías socio-religiosas de aquel país en la Edad Moderna. Para ello, se ha considerado más de una treintena de manuales escolares publicados entre 1973 y 2018, encuadrados en todas las leyes educativas vigentes en ese periodo y correspondientes a los dos niveles de educación secundaria (obligatoria y bachillerato). Su análisis se ha llevado a cabo considerando su lugar en la programación de cada ley educativa, el espacio que ocupan las
\end{abstract}

\footnotetext{
${ }^{1}$ Trabajo redactado con el apoyo de los proyectos de investigación HAR-2015-70147-R y PID2019-105070GB-I00, sufragados por el Ministerio de Economía y Competitividad y el Ministerio de Ciencia e Innovación del Gobierno de España. El autor desea agradecer a Miguel Somoza (UNED. Centro MANES. España) y a Elena Rodríguez Serrano (IES Ojos del Guadiana-Daimiel. España) su inestimable ayuda a la hora de facilitar la consulta de las fuentes del presente trabajo.

2 The paper was written with the support of the research projects HAR-2015-70147-R and PID2019-105070GB-I00, financed by the Ministry of Economy and Competitiveness and the Ministry of Science and Innovation of the Government of Spain. The author wishes to thank Miguel Somoza (UNED. MANES Center. Spain) and Elena Rodríguez Serrano (IES Ojos del Guadiana-Daimiel. Spain) for their invaluable help in facilitating the consultation of the sources for this work.

${ }^{3}$ Trabalho escrito com o apoio dos projetos de investigação HAR-2015-70147-R e PID2019-105070GB-I00, apoiados pelo Ministério de Economia e Competitividade e pelo Ministério da Ciência e Inovação do Governo da Espanha. O autor deseja agradecer a Miguel Somoza (UNED. MANES Center. Espanha) e Elena Rodríguez Serrano (IES Ojos del Guadiana-Daimiel. Espanha) por sua inestimável ajuda para facilitar a consulta às fontes deste trabalho.
} 
http://doi.org/10.15359/ree.25-3.21

http://www.una.ac.cr/educare

educare@una.ac.cr

explicaciones en cada unidad didáctica y la interpretación concedida al papel que cada minoría jugó en la España del Antiguo Régimen. El objetivo perseguido es definir cuáles han sido las líneas argumentales empleadas a la hora de introducir el devenir de ambos grupos sociales en enseñanza de la historia hispana de los siglos XVI y XVII. Resultados. El examen de tales materiales ha permitido constatar que el estudio de ambas minorías constituye un tema nuclear en la particular historia española. Sin embargo, ha podido observarse que apenas si se han producido cambios de relevancia a la hora de abordar su explicación. Ambos grupos son analizados primando consideraciones de tipo político e institucional, donde lo social y cultural queda relegado a un segundo plano. Discusión. La pervivencia de esas inercias discursivas no puede explicarse únicamente en función de la importancia que tiene el arraigo de las narrativas nacionalistas en la enseñanza de nuestro pasado, sino también a partir de la evidente desconexión entre historia enseñada/aprendida e historia investigada.

Palabras claves: Manuales escolares; enseñanza secundaria; historia de España en la Edad Moderna; minorías socio-religiosas; siglos XX-XXI; España.

\begin{abstract}
:
Introduction. Western societies face the challenge of introducing and developing educational methodologies in order to ease the integration of minorities and promote the attention to the diversity of an increasingly and heterogeneous group of students. History can contribute to this mission by analyzing the past of groups that were persecuted because of their origin, ideas, or beliefs. Methods. This paper examines the narratives and methodologies implemented in the last half-century in the several Spanish secondary education levels to inspect the history of Jew converts and Moriscos, the two main Spanish socio-religious minorities during the Early Modern Period. Conducting the study required analyzing more than thirty school textbooks; these texts were published between 1973 and 2018. They have been used in the legislative context defined by the four applicable education programs from 1970 to the present in the two secondary education levels in Spain (compulsory education and high school). The analysis of these contents was conducted considering their place in the general programming of each educational law, the space occupied by the explanation in each didactic unit, and the interpretation given to the role that both minorities played in Spain during the Early Modern Period. This paper aims to define the argumentative line used to introduce the evolution of both social groups in the teaching of Hispanic history in the 16th and 17th centuries. Results. Thanks to examining contents, exercises, and complementary materials, we can verify that the study of both minorities is one of the most important issues in Spanish history in the Early Modern Period. However, it has been observed that, in the last fifty years, there are no significant modifications in textbooks used in secondary education. Both groups are examined prioritizing political and institutional considerations, where the social and cultural issues are relegated to the background. Discussion. The persistence of these discursive inertias cannot be just explained from the importance of nationalist narratives in the way our history is narrated, but also on the basis of the obvious lack of connection between taught/learned and researched history.
\end{abstract}

Keywords: Textbooks; secondary education; Early Modern Spain history; religious-cultural groups; 20th-21st centuries, Spain. 


\begin{abstract}
Resumo:
Introdução. As sociedades ocidentais enfrentam o desafio de desenvolver metodologias de ensino centradas na integração das minorias e na atenção à diversidade de um corpo discente cada vez mais heterogéneo. A história pode contribuir para esta missão, especialmente quando estuda o passado de grupos que foram perseguidos pela sua origem, ideias ou crenças. Método. Este artigo analisa as narrativas e metodologias utilizadas no último meio século, nas escolas secundárias espanholas para analisar a história dos judeos convertidos e moriscos (mouros), as duas principais minorias socio-religiosas daquele país na Idade Moderna. Para tal, foram analisados mais de trinta manuais escolares publicados entre 1973 e 2018, enquadrados em todas as leis educativas em vigor nesse período e correspondentes aos dois níveis do ensino fundamental (obrigatório e bacharelato). A análise destes conteúdos foi realizada considerando o seu lugar na programação geral de cada lei educativa, o espaço ocupado pelas explicações em cada unidade didática e a interpretação dada ao papel que cada minoria desempenhou na Espanha do Antigo Regime. O objetivo é definir as linhas de argumentação utilizadas na introdução da evolução de ambos grupos sociais no ensino da história hispânica nos séculos XVI e XVII. Resultados. Uma análise destes materiais demonstrou que o estudo de ambas minorias constitui uma questão nuclear na história espanhola. No entanto, foi possível observar que quase não houve alterações da narrativa historiográfica. Ambos os grupos são analisados segundo uma perspetiva política e institucional. A sua caracterização social e cultural é relegada para segundo plano. Discussão. A sobrevivência desta inércia discursiva não pode ser explicada apenas pelo enraizamento das narrativas nacionalistas no ensino do nosso passado, mas também em termos da evidente desconexão entre história ensinada/aprendida e história investigada.
\end{abstract}

Palavras chave: Manuais escolares; ensino fundamental; história da Espanha na idade moderna; grupos sócio-culturais; séculos XX-XXI; Espanha.

\title{
Introducción
}

Grupos judeoconversos y moriscos fueron las dos grandes minorías socio-religiosas de la España del Antiguo Régimen (siglos XV al XVIII) (Amelang, 2011; Domínguez Ortiz, 1978; Domínguez Ortiz y Vincent, 1978). Su aparición en la historia de Castilla y Aragón se produce como consecuencia de la puesta en marcha de las políticas de corte autoritario desarrolladas desde el reinado de los Reyes Católicos. En ese contexto, la progresiva configuración del Estado absoluto exigía la eliminación de barreras jurisdiccionales y el desarrollo de políticas tendentes a asegurar la existencia de un aparato estatal fuerte y arraigado. La consolidación de aquel programa político-administrativo y económico también requirió de actuaciones en materia social y religiosa. Lejos de ser exclusivas de los reinos ibéricos, las políticas de corte uniformador fueron propias de todos los Estados europeos del siglo XVI y se acrecentaron a partir de las luchas religiosas que siguieron a la fragmentación de la cristiandad europea. En las coronas de Castilla y Aragón, ese deseo homogeneizador en materia religiosa tuvo un primer exponente en los decretos de conversión de los judíos (1492). A penas diez años después, y como consecuencia de la conquista de Granada, los mudéjares granadinos y castellanos fueron obligados a seguir el mismo camino. El ciclo se completó en 1526, cuando los musulmanes de la Corona de Aragón también fueron obligados a convertirse. 
http://doi.org/10.15359/ree.25-3.21

http://www.una.ac.cr/educare

educare@una.ac.cr

Aunque el camino elegido por cada grupo divergió -la diáspora judía fue más amplia- las conversiones dieron lugar a la aparición de dos nuevos grupos sociales: judeoconversos y moriscos. Oficialmente cristianos, ambos colectivos se vieron sometidos a un proceso de discriminación en el que se operaron factores de índole interno y externo. De entre los primeros cabe señalar la irreductibilidad religiosa de algunos de los convertidos, algo que desembocó en el desarrollo de prácticas heréticas. Entre las consideraciones de tipo exógeno cabe señalar el arrinconamiento sociopolítico al que fueron sometidos los nuevos cristianos, si bien hay que señalar que ese proceso de segregación fue salvado de manera más habilidosa por los convertidos de la ley de Moisés, en parte por su mayor capacidad económica. La conquista de Granada, el nacimiento de la Inquisición o el asunto de la limpieza de sangre son solo algunos de esos asuntos que están irremediablemente unidos a la particular historia de los nuevamente convertidos, motivo por el que ambos grupos han adquirido la consideración de sujeto histórico individualizado.

Este artículo tiene como objetivo delimitar cuáles han sido los principales argumentos discursivos y métodos didácticos empleados para introducir y contextualizar la vida de los grupos judeoconversos y los moriscos en la enseñanza de la historia española de los siglos modernos. Se persigue conocer cuál ha sido la imagen que, de ambas minorías, han tenido las diferentes generaciones de estudiantes de España del último medio siglo y averiguar si en ese lapso ha habido una evolución en las narrativas desplegadas para analizar su trascendencia histórica.

El marco conceptual en el que se ha basado el trabajo que se desarrolla a continuación parte del empleo de dos fuentes principales, bien diferenciadas, pero complementarias: la literatura escolar y la legislación educativa. El estudio de los libros de texto constituye una línea de trabajo de enorme calado, tanto en el continente europeo como en Estados Unidos y Latinoamérica (Borre Johnsen, 1996; Choppin, 1992; Foster, 2011), a pesar de que la diversidad temática específica de cada región o país ha conducido al desarrollo de líneas argumentativas dispares. Pese a las evidentes diferencias, siempre ha primado una interpretación del pasado ligada a la construcción de la identidad nacional (Gómez Carrasco y Molina Puche, 2017). Con una tradición que comienza a estar consolidada, en España, el análisis de los libros de texto no ha permanecido en posiciones estáticas (Valls Montés, 2001, 2007). En ese sentido, puede decirse que ha seguido un camino muy similar al transitado por las distintas escuelas historiográficas radicadas a ambos lados del Atlántico y que, incluso, ha sido capaz de exportar y desarrollar propuestas metodológicas propias (Gómez Carrasco et al., 2014). La investigación sobre libros de texto en España no solo ha permitido conocer cuestiones tocantes a la propia práctica docente; también ha proporcionado elementos de juicio para conocer cómo funciona la sociedad española en la actualidad y cómo, desde el plano educativo, se ha hecho frente a los procesos de modernización socioeconómica y de transición política en el último medio siglo. 
http://doi.org/10.15359/ree.25-3.21

http://www.una.ac.cr/educare educare@una.ac.cr

Tabla 1: La historia moderna en la enseñanza secundaria en España (1970-2019) *

\begin{tabular}{|c|c|c|c|c|c|c|}
\hline LEGISLACIÓN & $7^{\circ} \mathrm{EGB} / 1^{\circ} \mathrm{ESO}$ & $8^{\circ} \mathrm{EGB} / 2^{\circ} \mathrm{ESO}$ & $1^{\circ} \mathrm{BUP} / 3^{\circ} \mathrm{ESO}$ & $2^{\circ} \mathrm{BUP} / 4^{\circ} \mathrm{ESO}$ & $3^{\circ} \mathrm{BUP} / 1^{\circ} \mathrm{Bach}$ & $\mathrm{COU} / 2^{\circ} \mathrm{Bach}$ \\
\hline \multirow{2}{*}{$\begin{array}{l}\text { LGE } \\
\text { Ley General de } \\
\text { Educación }^{(1)}\end{array}$} & \multicolumn{2}{|c|}{ Ciencias sociales } & $\begin{array}{c}\text { Historia de las } \\
\text { civilizaciones y del } \\
\text { arte }\end{array}$ & & $\begin{array}{l}\text { Geografía e historia de } \\
\text { España y de los países } \\
\text { hispánicos }\end{array}$ & \multirow{2}{*}{$\begin{array}{l}\text { Historia } \\
\text { del mundo } \\
\text { contemporáneo }\end{array}$} \\
\hline & Historia moderna & $\begin{array}{l}\text { Historia } \\
\text { contemporánea }\end{array}$ & $\begin{array}{l}\text { Historia moderna } \\
8 \text { ítems de } 32\end{array}$ & & $\begin{array}{l}\text { Historia moderna } \\
7 \text { items de } 32\end{array}$ & \\
\hline \multirow{2}{*}{$\begin{array}{l}\text { LOGSE } \\
\text { Ley Orgánica General de } \\
\text { Ordenación del Sistema } \\
\text { Educativa }^{(3)}\end{array}$} & \multicolumn{2}{|c|}{ Ciencias sociales, geografía e historia } & & $\begin{array}{l}\text { Ciencias sociales, geografía } \\
\text { e historia }\end{array}$ & \multirow{2}{*}{$\begin{array}{l}\text { Historia del mundo } \\
\text { contemporáneo }{ }^{(4)} \\
\text { (itinerario humanidades } \\
\text { y ciencias sociales) }\end{array}$} & $\begin{array}{l}\text { Historia } \\
\text { (de España) } \\
\text { (materia común) }\end{array}$ \\
\hline & $\begin{array}{l}\text { Prehistoria } \\
\mathrm{H}^{\text {a }} \text { Antigua }\end{array}$ & Historia Medieval & & $\begin{array}{l}\text { Historia moderna } \\
\text { Historia contemporánea }\end{array}$ & & $\begin{array}{l}\text { Historia moderna } \\
1 \text { ítem de } 7\end{array}$ \\
\hline \multirow{2}{*}{$\begin{array}{l}\text { LOCE } \\
\text { Ley Orgánica de Calidad } \\
\text { de la Educación }{ }^{(5)}\end{array}$} & \multicolumn{2}{|c|}{ Ciencias sociales, geografía e historia } & & $\begin{array}{l}\text { Ciencias sociales, geografía } \\
\text { e historia }\end{array}$ & \multirow{2}{*}{$\begin{array}{l}\text { Historia del mundo } \\
\text { contemporáneo }^{(4)} \\
\text { (itinerario } \\
\text { humanidades y } \\
\text { ciencias sociales) }\end{array}$} & \multirow{2}{*}{$\begin{array}{l}\text { Historia de España } \\
\text { (materia común) } \\
\text { Historia moderna } \\
4 \text { items de } 16\end{array}$} \\
\hline & $\begin{array}{l}\text { Prehistoria } \\
\text { historia antigua }\end{array}$ & Historia media & & $\begin{array}{l}\text { Historia moderna } \\
4 \text { items de } 15\end{array}$ & & \\
\hline \multirow{2}{*}{$\begin{array}{l}\text { LOE } \\
\text { Ley Orgánica de } \\
\text { Educación }^{(6)}\end{array}$} & \multicolumn{2}{|c|}{ Ciencias sociales, geografía e historia } & & $\begin{array}{l}\text { Ciencias sociales, geografia } \\
\text { e historia }\end{array}$ & \multirow{2}{*}{$\begin{array}{l}\text { Historia del mundo } \\
\text { contemporáneo }{ }^{(4)} \\
\text { (itinerario } \\
\text { humanidades y } \\
\text { ciencias sociales) }\end{array}$} & \multirow{2}{*}{$\begin{array}{l}\text { Historia de España } \\
\text { (materia común) } \\
\text { Historia moderna } \\
2 \text { items de } 8\end{array}$} \\
\hline & $\begin{array}{l}\text { Prehistoria } \\
\text { Historia Antigua }\end{array}$ & $\begin{array}{l}\text { Historia Medieval } \\
\text { Historia } \\
\text { Moderna }\end{array}$ & & $\begin{array}{l}\text { Historia Moderna } \\
\text { Historia Contemporánea }\end{array}$ & & \\
\hline \multirow{3}{*}{$\begin{array}{l}\text { LOMCE } \\
\text { Ley Orgánica para la } \\
\text { Mejora de la Calidad } \\
\text { Educativa }^{(7)}\end{array}$} & \multicolumn{4}{|c|}{$\begin{array}{l}\text { Ciencias sociales, } \\
\text { geografía e historia }\end{array}$} & & \\
\hline & \multicolumn{3}{|c|}{ PRIMER CICLO ${ }^{(8)}$} & $4^{\circ} \mathrm{ESO}$ & & \multirow{2}{*}{$\begin{array}{l}\text { Historia de España } \\
\text { (materia común) } \\
\text { Historia moderna } \\
2 \text { bloques de } 12\end{array}$} \\
\hline & $\begin{array}{l}\text { Prehistoria } \\
\text { Historia antigua }\end{array}$ & Historia medieval & Historia moderna & $\begin{array}{l}\text { Historia moderna } \\
\text { Historia contemporánea }\end{array}$ & & \\
\hline
\end{tabular}

(1) Ley 12/1970, de 4 de agosto, General de Educación y Financiamiento de la Reforma Educativa (Jefatura del Estado, 1970).

(2) Obligatoria en la OPCIÓN A (junto a Literatura).

(3) Ley Orgánica 1/1990, de 3 de octubre, de Ordenación General del Sistema Educativo (Jefatura del Estado, 1990).

(4) La ley contempla 3 itinerarios (en LOE modalidades): Artes, Ciencia y Tecnología y Humanidades y Ciencias Sociales. En LOE, la modalidad Artes se articula en dos vías: Artes plásticas, imagen y diseño y Artes plásticas, música y danza.

(5) Ley Orgánica 10/2002, de 23 de diciembre, de Calidad de la Educación (Jefatura del Estado, 2002).

(6) No entra en vigor. Ley Orgánica 2/2006, de 3 de mayo, de Educación (Jefatura del Estado, 2006).

(7) ey Orgánica 8/2013, de 9 de diciembre, para la mejora de la calidad educativa (Jefatura del Estado, 2013).

Nota: Elaboración propia.

El otro pilar conceptual en el que se apoyan estas líneas es el análisis de las leyes bajo las que se ha gobernado el sistema educativo español desde el tard ofranquismo hasta la actualidad. La Tabla 1 sintetiza lo esencial de cada una de las normas que han regido en ese tiempo, especialmente en lo relativo a la enseñanza de la historia. A pesar de que se han experimentado significativas transformaciones, el manual escolar continúa siendo una herramienta con un fuerte arraigo (Valls Montés, 1998, 2007, 2008). Su presencia como elemento referencial en el aula no ha sido ajena al debate (Fernández Palop y Caballero García, 2017). En este sentido, 
http://doi.org/10.15359/ree.25-3.21

http://www.una.ac.cr/educare

educare@una.ac.cr

la progresiva implantación de nuevas metodologías docentes ha reducido el peso de los manuales en beneficio de otro tipo de recursos, especialmente en los últimos veinte años, desde la implantación de la LOGSE (Tabla 1). Desde entonces, las sucesivas leyes educativas y el desarrollo normativo establecido por cada una de las comunidades autónomas que conforman el Estado español han dejado cierto margen de maniobra a profesorado y centros educativos, especialmente a la hora de definir contenidos y seleccionar y emplear materiales para el ejercicio de la práctica docente. Dicha práctica ha llevado a la diversificación de la oferta (Valls Montés, 1998), pero ha generado inconvenientes relacionados con la viabilidad económica de muchas de las editoriales. Por su parte, y en un plano estrictamente docente, ha conducido a un proceso de repliegue (muy posiblemente ni esperado ni deseado), que ha llevado a muchos centros y docentes a refugiarse en el propio libro de texto, dado que su seguimiento asegura el cumplimiento casi íntegro de los currículos oficiales (Gómez Carrasco et al., 2014).

En ese contexto general, los libros de historia también han sido objeto de un tratamiento individualizado. En ellos, y tomando como referencia el general desdén hacia los contenidos humanísticos, se detecta una marcada tendencia al presentismo, materializada en la minusvaloración de todo lo anterior a la época contemporánea (Rodríguez Garrido, 2012). Junto a ello, las narrativas desplegadas han transitado desde una historia chovinista a una visión que, en los últimos años, ha reforzado el eurocentrismo (López Facal, 2010), algo que no resulta incompatible con un general repliegue de los contenidos en torno a "la historia de la propia región ... no pocas veces con un sentido nacionalista” (Domínguez Ortiz, 1997, p. 23).

\section{Método}

Como ha quedado indicado, este artículo parte de la consideración conjunta de legislación, programas oficiales y contenidos incluidos en los libros de texto empleados en nuestro país en enseñanza secundaria durante el último medio siglo. En ese sentido, se apoya en la metodología propia de la corriente que estudia los manuales escolares de historia y recupera el análisis de dichos materiales en un tiempo medio/largo, cuestión que ya ha sido tratada, si bien con enfoques temáticos diferentes (López Facal, 2010). En concreto, se han tomado como referencia treinta y nueve manuales escolares (cuyas fechas de publicación extremas son 1973 y 2018), que han sido comercializados por las principales editoriales españolas dedicadas a la elaboración de libros de texto (Tabla 2). El trabajo con tales materiales se vio facilitado por la colaboración del Centro MANES (Centro de Investigación de Manuales Escolares), de la Universidad Nacional de Educación a Distancia (UNED), con sede en Madrid. En todo momento se ha intentado configurar una selección que fuera respetuosa con cuatro criterios fundamentales: la proporcionalidad temporal, el equilibrio geográfico-regional (se han seleccionado ediciones relativas a diferentes comunidades autónomas), la distribución lo más equitativa posible entre las etapas obligatoria y no obligatoria del ciclo de enseñanza secundaria y el recurso a un número lo más amplio y variado posible de editoriales. 
http://doi.org/10.15359/ree.25-3.21

http://www.una.ac.cr/educare educare@una.ac.cr

Tabla 2: Manuales analizados. Distribución por editorial/ley educativa

\begin{tabular}{|c|c|c|c|c|}
\hline Editorial & LGE & LOGSE & LOE & LOMCE \\
\hline Anaya & 2 & & & 2 \\
\hline Bruño & 1 & & & \\
\hline $\mathrm{ECIR}$ & 1 & & & \\
\hline Edebé & & & & 1 \\
\hline Edelvives & 1 & 1 & 1 & \\
\hline Editext & & 1 & & \\
\hline Ed. Libros Activos & & 1 & & \\
\hline Ed. Magisterio Español & 2 & & & \\
\hline Inst de Ciencias de la Ed. (USAL) & 1 & & & \\
\hline McGraw-Hill & & 1 & & \\
\hline $\begin{array}{l}\text { MEC. Inst. Nacional de } \\
\text { Bachillerato }\end{array}$ & 2 & & & \\
\hline Oxford & & 1 & 1 & 1 \\
\hline Santillana & 3 & 1 & 1 & 1 \\
\hline SM & 1 & 1 & 2 & 1 \\
\hline Vicens Vives & 4 & & 2 & 1 \\
\hline TOTAL & 18 & 7 & 7 & 7 \\
\hline
\end{tabular}

Nota: Elaboración propia.

El resultado es una muestra amplia y equilibrada en el tiempo, que se extiende en un arco cronológico que comprende los cuarenta y ocho años en los que se han desarrollado LGE, LOGSE, LOE y LOMCE. Su distribución temporal y la comparación con los periodos de vigencia de cada ley (Tabla 1; Figura 1) informan de cierta correspondencia, si bien es necesario remarcar que existe una infrarrepresentación de los manuales LOGSE, debido al escalonamiento al que fue sometida la implantación de aquella norma, aprobada en 1990, pero no vigente para los niveles educativos aquí estudiados hasta el curso 1995-1996. 
http://doi.org/10.15359/ree.25-3.21

http://www.una.ac.cr/educare

educare@una.ac.cr

Figura 1: Comparativa (en \%) vigencia leyes educativas/manuales analizados

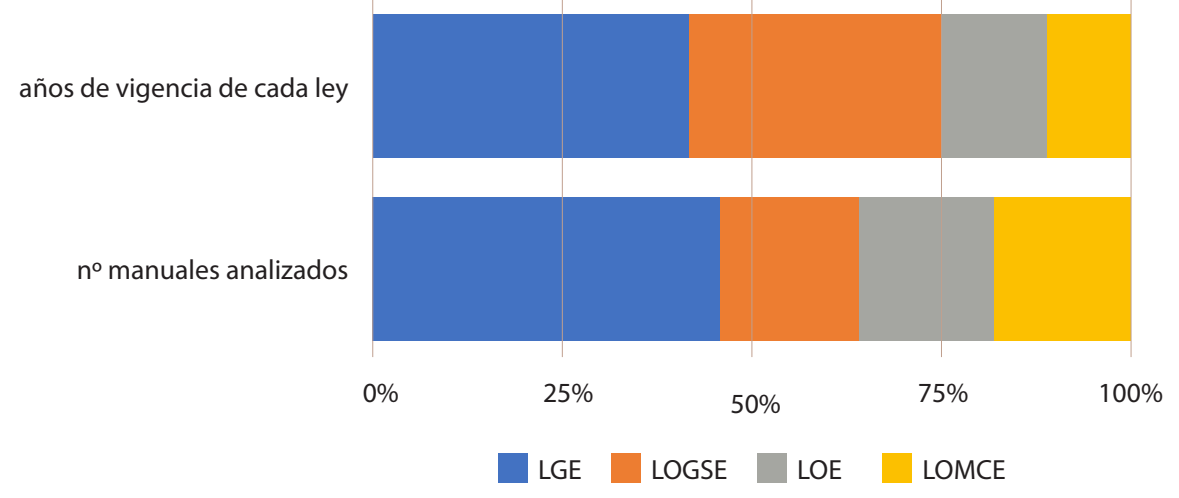

Nota: Elaboración propia.

Cada uno de los textos sometidos a análisis ha sido clasificado, catalogado y adscrito a la correspondiente ley bajo la que se ha desarrollado. Ello ha permitido evaluar la estructura inicial de cada manual y la importancia que los autores y autoras correspondientes concedieron a los temas referentes a la Edad Moderna (siglos XV a XVIII). En ese sentido, y a pesar de ser objeto de reubicaciones en los currículos oficiales (Henarejos Carrillo, 2016), ha podido constatarse que los contenidos relativos a la época moderna apenas han experimentado cambios en los últimos cincuenta años (Tabla 1). De ello han dado cuenta los autores y autoras que han analizado tanto la legislación (Gómez Carrasco, 2014; Molina et al., 2014), como el empleo de instrumentos docentes relativos al Antiguo Régimen (Martínez et al., 2009). En relación con los asuntos tratados, han acaparado cierta atención las explicaciones relativas a los Reyes Católicos y a la figura de Felipe II (Valls Montés, 2007), así como aspectos e instituciones propios de aquella época como la Inquisición o el sistema polisinodial hispano. En los últimos años también han visto la luz aportaciones relativas a personajes como Carlos $\mathrm{V}$ y a etapas y acontecimientos concretos como el Descubrimiento, la expansión ultramarina hispano-portuguesa o la Guerra de Sucesión (García González et al., 2016; Gómez Carrasco et al., 2016). Sin embargo, se ha dicho muy poco acerca de las minorías socio-religiosas.

Con el objetivo de paliar ese déficit, esta investigación ha individualizado esos contenidos y los ha sometido a revisión atendiendo a varios criterios:

a) en primer lugar, se han separado los temas -apartados, más bien- relativos a la comunidad judeoconversa, de aquellos otros relativos al colectivo morisco. En ese sentido, ha podido constatarse que la explicación conjunta, paralela y comparada de ambos grupos ha sido prácticamente inexistente. 
http://doi.org/10.15359/ree.25-3.21

b) se han analizado los contenidos teóricos incluidos en cada manual y se ha procedido a su posterior clasificación. Para ello, se han considerado etapas cronológicas, referencias específicas a hechos concretos y explicaciones de tipo estructural, que remiten al desarrollo en el tiempo largo de cada una de las minorías estudiadas.

c) se han estudiado los materiales complementarios aportados por los autores y las autoras de cada manual. En ese sentido, se han individualizado diferentes categorías (textos, imágenes, cartografía...) cuyo estudio se especifica en apartados anteriores.

d) finalmente se han sometido a revisión los ejercicios prácticos propuestos en cada tema, en su mayoría relacionados con la evaluación y autoevaluación de los contenidos teóricos previamente incluidos en el manual mismo.

\section{Análisis de resultados}

En la práctica docente, se admite que el estudio de cualquier categoría histórica debe ir precedida de su definición, ubicación espacial y contextualización cronológica. Por tanto, resulta lógico esperar que cualquier libro de texto que analice la historia de las minorías judeoconversa y morisca se pregunte por tales parámetros. La reflexión anterior, por obvia, no es intrascendente porque ha podido detectarse que, salvo en honrosas excepciones, la presencia de ambas minorías no es individualizada. Así, prácticamente todos los textos analizados definen a las personas judeoconversas y moriscas en el marco de las explicaciones tocantes al reinado de los Reyes Católicos, retomando contenidos previamente explicados en los temas relativos a la sociedad bajomedieval y al avance de la conquista cristiana de los reinos musulmanes. En ese contexto, los libros empleados en la Educación General Básica (EGB) (LGE) son los que más atención prestan a la hora de caracterizar sociológicamente a ambos grupos, si bien es cierto que, a veces, recurren a ciertos tópicos que, por otra parte, se encuentran muy arraigados aún en la cultura popular hispana. De los grupos judíos se destaca su particular organización en barrios separados, su carácter urbano, su actividad eminentemente ligada al comercio y al préstamo de dinero y la hostilidad -en algunos manuales se habla literalmente de odio- que despertaron entre la población cristiana. También se insiste en la protección que les dispensó la Corona, pero siempre en contraposición a la mención al general deterioro de la convivencia que se dio a finales del siglo XV. Algunos textos establecen una tímida diferenciación con respecto a los grupos mudéjares al afirmar que la animadversión hacia los judíos era mayor que en el caso de aquellos. De los propios sectores musulmanes, se resalta su laboriosidad, los bajos salarios que cobraban y la ligazón al régimen señorial de quienes habitaban en los reinos de la Corona de Aragón.

Por lo demás, y en un plano estrictamente historiográfico, la distinción entre grupos judíos/ conversos por un lado y mudéjares-musulmanes/moriscos por otro, se concreta de manera correcta en términos generales. Es cierto que en algunos textos la especificación terminológica 
http://doi.org/10.15359/ree.25-3.21

http://www.una.ac.cr/educare

educare@una.ac.cr

asociada al diferente estatus legal y religioso de cada grupo se confunde. Tanto es así que en alguno de los manuales analizados llega a leerse que fueron los moriscos los obligados a convertirse en 1502, cuando, en realidad, ese es el nombre con el que, más tarde, se conocería a los mudéjares/musulmanes que optaron por no emigrar y por convertirse al cristianismo.

Dejando aparte los aspectos generales, el abordaje metodológico que se ha desarrollado en esta investigación ha permitido constatar que, más allá de consideraciones temáticas y de aspectos historiográficos concretos, el principal hilo organizativo de los contenidos es el orden cronológico. En ese sentido, el contenido de los manuales resulta previsible para todo aquel que los analice desde un punto de vista especializado. Sin embargo, parece adecuado para trasladar el contenido al alumnado de enseñanza media de una manera fácilmente asumible. La expulsión de los grupos judíos siempre es analizada en el contexto de la unificación religiosa pretendida por Isabel y Fernando. Se trata de un tema que pierde presencia a medida que la fecha de publicación de los textos estudiados se acerca al presente, algo que resulta especialmente llamativo en el caso de las manuales ESO de la LOE y LOMCE (en Bachillerato es menos visible). Sin embargo, no es menos cierto que el análisis de este tema sirve a las autorías más actuales para introducir conceptos historiográficos como cristiano viejo; converso; judeoconversos; Sefarad; sefardí... que, sin duda, facilitan que el alumnado advierta y conozca la existencia de un lenguaje específico en relación con la historia de la minoría de origen judío.

En general, se observa poca concreción a la hora de calcular cuántas personas judías optaron por el éxodo y cuántas decidieron convertirse. Sí captan más atención (y concitan mayor unanimidad) las menciones al destino de los grupos expulsados, aspecto que conduce al análisis del fenómeno de la diáspora sefardí. En tales explicaciones, es tónica general que se centre la atención de manera en aquellos aspectos relacionados con la cohesión cultural del grupo y en la importancia que ese sentimiento supuso para su supervivencia cultural, tanto en la propia Edad Moderna, como en la época contemporánea, e, incluso, en la actualidad.

Tras analizar el destierro, los textos consultados se centran en sus consecuencias. Se insiste en el perjuicio económico que supuso el exilio. En ese contexto, se localizan argumentos que no solo inciden en la pérdida económica, sino en el menoscabo derivado de lo que podría calificarse como pérdida de oportunidad. De hecho, hay manuales en los que se desliza la idea de que la medida pudo constituir un error, al coincidir con un momento (expansión ultramarina) en el que los reyes estaban necesitados de buenos hombres de negocios. No obstante, el análisis no se circunscribe únicamente a la cuestión económica. También es necesario señalar que hay estudios que valoran los efectos de la expulsión y posterior persecución de los conversos en términos de pérdida intelectual, algo especialmente visible cuando, de manera puntual, se analizan casos concretos de personajes como ocurre con Juan Luis Vives, cuya familia, conversa fue víctima del celo inquisitorial en su ciudad natal. 
http://doi.org/10.15359/ree.25-3.21

Como veremos que ocurre en el caso de los grupos moros -si bien aquí de manera más incisiva-, también se apunta que una parte significativa de los convertidos solo adoptó su nueva religión de manera aparente, y volvieron a las prácticas religiosas de sus generaciones antepasadas. Se trata de una realidad que sirve a la totalidad de textos para conectar el análisis del fenómeno converso con las explicaciones relativas a la Inquisición. En relación con ello, es loable el intento de encuadrar la actuación de los Reyes Católicos; primero contextualizando su política de persecución de las minorías sociorreligiosas en el marco general europeo. Segundo, mostrando al alumnado que la creación del Tribunal del Santo Oficio no fue algo exclusivo de los reinos hispánicos, sino que retomó la tradición de una institución con largo recorrido en Europa. A pesar de ello, quienes abordan este aspecto también señalan las diferencias entre las inquisiciones europeas e hispana. Nos situamos ante un enfoque que queda plasmado en los textos publicados al amparo de todas las leyes educativas objeto de estudio. En ese sentido, el desarrollo de contenidos es mayor en el bachillerato que en los niveles obligatorios. En el caso de esta última etapa los manuales ESO desarrollan un análisis que, en términos generales, es más laxo que en EGB.

La inquisición hispana es presentada como un instrumento al servicio de la política de unidad religiosa de los Reyes Católicos. En general, se especifica bien su fecha de fundación (1478) y el lugar y momento (Sevilla, 1480) donde comenzó su andadura efectiva, así como la posterior extensión de su jurisdicción a la Corona de Aragón. Igualmente se suele recoger la fecha de creación del Consejo de la Inquisición, aunque, en ocasiones, se confunde el establecimiento del Tribunal con la creación del Consejo mismo. Por lo demás, no falta la presencia de tópicos en relación con la actuación del Santo Oficio, principalmente relativos al intento de encuadrar su actuación en un ambiente de terror, comentarios que, por otra parte, son más aislados de lo que podría pensarse en principio. Debe señalarse también que, como ocurre en el caso de los grupos judíos, se emplean conceptos historiográficos como sambenito o auto de fe. A pesar de su escasa presencia, puede afirmarse que su mera utilización constituye un tímido -pero remarcable- intento de abordar la explicación del procedimiento inquisitorial, algo que resulta interesante para los niveles educativos que se analizan aquí. En algunos manuales, el asunto incluso es analizado con detalle y ocupa un espacio específico, como parte de recuadros de refuerzo o actividades y lecturas complementarias, donde es evidente la pérdida de interés que, en relación con este asunto, se da a partir de los años 2000.

Más allá de estos aspectos, las menciones a la minoría conversa desaparecen por completo en los textos analizados, como si descendientes de los antiguos judíos nada hubieran aportado a la historia hispana, aparte, claro está, de ser víctimas de la expulsión decretada en 1492. El fenómeno converso queda, así, silenciado, minimizando la aportación posterior de dicho grupo a la historia de España, como si el destierro hubiera supuesto la solución definitiva y nada hubiera ocurrido con posterioridad en relación con este colectivo. 
http://doi.org/10.15359/ree.25-3.21

http://www.una.ac.cr/educare

educare@una.ac.cr

Algo similar ocurre en el caso morisco. A excepción de los ejemplos ya mencionados, la narrativa tocante a los sujetos convertidos de moros también comienza con referencias explícitas a la actuación de los Reyes Católicos. En ese marco, la guerra de conquista de Granada (14821493) ocupa un lugar destacado y constituye el preludio al análisis del propio asunto morisco. No obstante, conviene señalar que, en prácticamente todos los manuales consultados, el tema se encuadra en el contexto de expansión territorial y no de guerra religiosa. En ese sentido, más que a la expulsión de los judíos, se une a la conquista de Navarra (1512), a la ocupación de las islas Canarias (cuya fase realenga finalizó en 1496) e, incluso, a la muy posterior anexión de Portugal (1580). Nos situamos, pues, ante uno de esos temas, considerados clave, que es incluido en todos los currículos oficiales, en gran medida porque la conquista del reino nazarí constituye un referente clave en el marco de las denominadas narrativas nacionales españolas (Gómez Carrasco y Molina Puche, 2017). A pesar de ello, su tratamiento presenta contrastes. Frente a análisis claramente fácticos, marcados por una narración detallada de la contienda, con referencias concretas a la toma de plazas fuertes y con la inclusión de una cronología precisa, no es extraño encontrar textos en los que la guerra es mencionada de manera más sucinta. En esencia, se observa una descripción de los hechos que destaca por estar enfocada desde una óptica castellanocéntrica, en la que los acontecimientos y protagonistas relacionados con el bando nazarí o están ausentes o son tratados con superficialidad. Cuando las hay, las escasas menciones que se han localizado relativas al bando musulmán se enmarcan en el contexto de guerra civil que vivió el emirato granadino y son más propias de los manuales LGE que de los correspondientes a normas posteriores. Las menciones más explícitas remiten a Boaddil. En ese caso concreto, las referencias a su figura son comunes a manuales publicados en todo el arco cronológico considerado y correspondientes tanto a los niveles educativos obligatorios como a la etapa de bachillerato. Precisamente, es el último de los reyes nasríes quien protagoniza algunos de esos análisis cuyo uso continúa siendo exponente de la persistencia de esas narrativas nacionalistas a las que se hacía referencia más arriba. En ese sentido es frecuente observar al rey moro entregando las llaves de Granada a los reyes, acompañados, a su vez, de nobles, clérigos y soldados. Se trata de una escena que, sin duda, remite al famoso cuadro compuesto por Francisco Pradilla a finales del siglo XIX. Muy relacionado con ello, también cabe destacar el empleo -puntual, pero llamativo- de un leguaje pomposo y revestido de tintes épicos, como cuando, por ejemplo, se hace referencia al ondear de las banderas de los Reyes Católicos en las torres de la Alhambra. A la figura de Boabdil se asocia la utilización -implícita o manifiestade la noción de guerra contra el sujeto infiel. Su análisis conduce a comentar el ocaso de la civilización andalusí o el final de la Reconquista, algo que contrasta con la escasez de referencias a la realidad multiterritorial de la monarquía de los Reyes Católicos. Este último enfoque es más propio de textos publicados en las etapas LGE y LOGSE, dado que en los manuales posteriores se modulan estos presupuestos (a veces por omisión) y se presta más atención a las capitulaciones y no tanto a la guerra propiamente dicha. 
http://doi.org/10.15359/ree.25-3.21

El final de la contienda es abordado en todos los libros consultados. Una de las explicaciones más completas que se han localizado es la incluida en el manual de bachillerato LOE publicado por la editorial SM en 2009, donde, claramente, se opta por abordar el origen y desarrollo del conflicto desde un punto de vista multicausal. En el resto de los libros analizados, el análisis es menos ambicioso. No son extrañas las referencias al inicial carácter favorable que tuvieron las capitulaciones para la población mudéjar de Granada, aunque también se insiste en su temprano incumplimiento. También es frecuente -y he ahí uno de los problemas que presenta este aspectoque su análisis quede bruscamente interrumpido y que, en lo sucesivo (al menos hasta que se aborde la posterior rebelión de las Alpujarras), las referencias a la realidad morisca desaparezcan casi por completo, con lo cual se rompe toda posibilidad de que el alumnado conecte ambos contextos y aborde una comprensión lineal del fenómeno morisco en la España del XVI.

Por lo demás, la conversión de los mudéjares es presentada de un modo análogo a la de los judíos. Sin embargo, en este caso concreto se incide en que fue una consecuencia directa del progresivo deterioro y posterior incumplimiento de las capitulaciones que siguieron a la guerra de Granada. En ese sentido, son generalizadas las referencias a la intolerancia del cardenal Cisneros al que se suele hacer responsable del levantamiento que desembocó en el edicto de expulsión/conversión promulgado en 1502. En el extremo opuesto, apenas si se localizan referencias a Hernando de Talavera, figura que es contrapuesta, a veces de manera intencionadamente exagerada, a las del arzobispo de Toledo.

Junto a las conversiones de Granada/Castilla, pueden encontrarse referencias aisladas a mudéjares de la Corona de Aragón. En realidad, se trata de menciones más concretas, casi anecdóticas, algo que no deja de resultar llamativo, si se tiene en cuenta que aquel territorio censó a más de dos tercios de moriscos que posteriormente serían expulsados a inicios del siglo XVII. De hecho, pocos manuales hablan explícitamente de la pervivencia del fenómeno mudéjar en Aragón hasta 1525 y casi siempre coinciden con textos cuyas editoriales (Ecir y Edelvives), localizan su sede principal en ciudades de aquel territorio. Por motivos obvios, no siempre queda claro el carácter forzoso que los bautismos adquirieron allí. Solo nueve de los manuales analizados (23\%) contienen referencias directas al movimiento agermanado y en ellos el asunto morisco no siempre aparece reflejado. Cuando sí hay menciones a las conversiones, estas se presentan como el resultado indirecto de un conflicto que fue eminentemente urbano, pero que tuvo ramificaciones en el ámbito rural, donde los grupos moros de Valencia y Aragón fueron víctimas del levantamiento como consecuencia de su condición de vasallos de los señores contra los que se alzó la población burguesa y artesana.

Y llegados a ese punto, nuevo vacío. Como si la historia se frenara y los hechos se ralentizaran, los grupos protagonistas de nuestro estudio quedan diluidos en el seno de una narración que, en lo relativo al siglo XVI, obvia lo social y prima lo político. Prueba de ello es que los judeoconversos seguirán olvidados y los moriscos no volverán a a parecer hasta que se analice 
http://doi.org/10.15359/ree.25-3.21

http://www.una.ac.cr/educare

educare@una.ac.cr

la rebelión de Granada (1568-1570). Sin duda, es un tema clave y, junto con la expulsión de 16091614, el que más atención merece en el marco de las explicaciones relativas a las conversiones moras. En ese sentido, todos los programas oficiales - desde la LGE hasta la LOMCE- coinciden en señalar su importancia, tanto en la etapa obligatoria como en el bachillerato. Ese carácter central se vio especialmente reforzado a partir de 1982, cuando se publicó el nuevo currículo para ciclo superior de EGB. A partir de aquel momento, tanto los programas de primaria como los de Bachillerato Unificado Polivalente (BUP) equipararon contenidos y objetivos y encuadraron el tema en el marco de los problemas políticos de orden interno que acuciaron a Felipe II.

El análisis puramente historiográfico de los contenidos relativos a las minorías que son objeto de estudio en este trabajo ha permitido constatar que el paso de los años ha provocado la incorporación de explicaciones multicausales y el empleo de nuevos abordajes de enseñanzaaprendizaje. Todas ellas han sido observadas atendiendo a los principios metodológicos formulados en líneas precedentes. Sin embargo, y respondiendo a esas mismas preguntas de investigación, puede decirse que el grueso de la narrativa en torno a este asunto ha permanecido anclado. Sin duda, es algo que sorprende porque la historiografía investigadora dedicada al asunto morisco ha avanzado de manera decidida en la comprensión de dicho tema. Son muy pocos los autores o autoras de textos escolares que relacionan el estallido de la revuelta con sus causas remotas: las conversiones de principios de siglo. Solo en una ocasión se hace referencia explícita a la postergación de la puesta en marcha de las medidas tomadas en 1526 por Carlos V para asimilar a los moriscos, cuestión que la historia considera básica a la hora de entender la revuelta alpujarreña. Sí resulta más frecuente que las causas de la rebelión se sitúen en la negativa morisca a aceptar la imposición de las disposiciones aculturadoras que puso en marcha Felipe II a partir de 1567, y que, en realidad, fueron continuadoras de las que quiso implantar su padre y predecesor. A pesar de ello, esas explicaciones no suelen contextualizar aquellas órdenes en un marco lo suficientemente amplio como para permitir que el alumnado comprenda que el problema surge años atrás, precisamente en el reinado del césar Carlos. En ese sentido, la negativa morisca a la asimilación se plantea, casi siempre, en términos negativos: es la población morisca la que no se asimila y no la sociedad castellana la que no puede ni quiere asimilarla más allá del canon marcado por su propia identidad.

No obstante, y aunque de manera tímida, sí se han localizado manuales que emplean argumentos complementarios. En tal caso, la mayor parte de los cambios que se introducen se dan en el tránsito del siglo XX al XXI y se materializan en la progresiva incorporación de conceptos -nuevos por aquel entonces- que permitieron al alumnado comprender el asunto de una manera más amplia. Desde un punto de vista estrictamente cronológico, son consideraciones que coincidieron con el proceso de implantación de la LOGSE. No obstante, tendrían un recorrido innegable en el desarrollo de leyes posteriores, especialmente en la LOE, cuyo currículo contempló de manera expresa la necesidad de valorar los fenómenos morisco y 
http://doi.org/10.15359/ree.25-3.21

converso. Sin duda, la normativa gubernamental y la posterior ordenación de los contenidos ha influido de manera clara en el recurso a la multicausalidad a la hora de analizar los orígenes del conflicto. Sin embargo, es necesario aclarar dos cuestiones. En primer lugar, que las directrices oficiales no siempre son seguidas a rajatabla, ya que hay manuales publicados desde 2000 en adelante que presentan los mismos déficits analíticos que los publicados al amparo de la LGE. Junto a ello, es justo reconocer que, en muchos casos, el empleo de esas nuevas categorías discursivas es anterior a la promulgación de las normas citadas y bebe de manera directa del avance historiográfico, que, a finales del siglo XX, permitió que el asunto morisco fuera analizado (y comprendido) de una manera más global. No en vano uno de los manuales más completos es el de editorial Anaya, publicado para tercer curso de BUP en 1999, antes, por tanto, de la implantación definitiva de la LOGSE.

Tampoco hay unanimidad a la hora de abordar el papel desempeñado por los protagonistas de la contienda. Es clara la relevancia que se otorga a don Juan de Austria, el generalísimo de Felipe II. Su presencia en los textos es abrumadora antes de la LOGSE. Todos los manuales LGE lo citan mientras que, en los concebidos al amparo de leyes posteriores, esas apariciones tienden a difuminarse $y$, en todo caso, pierden las connotaciones épicas de los manuales del tardofranquismo y años de la Transición. En el extremo opuesto, los libros que mencionan a los otros grupos protagonistas de la guerra son relativamente escasos, apenas cuatro. Muy poco si de lo que se trata es de mostrar el conflicto en todas sus dimensiones.

También son escasas las referencias a las consecuencias que llevó aparejada la victoria de Felipe II sobre los grupos sublevados. El destierro a Castilla sobrevuela de manera superficial por algunos manuales, pero apenas si es mencionado de manera expresa. En su lugar, se utilizan (cuando se emplean) fórmulas más difusas, a veces ambiguas, en las que genéricamente se alude a la dispersión poblacional, pero sin especificar el destino final de los expulsados. Tampoco se presta mucha atención a la repoblación posterior de Granada, de tal manera que la particular historia del antiguo reino nazarí queda, otra vez, bruscamente interrumpida tras la salida de las gentes vencidas de Granada. Finalmente, cabe señalar que los textos tampoco son precisos en relación con las cifras de sujetos expulsados. De hecho, quienes ofrecen datos al respecto son minoría, al respecto, uno de los manuales más concretos es el de Bachillerato LOE de la editorial Vicens Vives publicado en 2010.

Finalmente, el destierro. Su desarrollo se encuadra en las explicaciones relativas al reinado de Felipe III, aunque, también es tratado en los temas que analizan la crisis del XVII, especialmente en los manuales LGE (anteriores a 1990). El proceso de expulsión de los moriscos es datado en 1609, dando por buena -y única- la fecha que marca el inicio del destierro. No en vano son muy pocos -todos ellos publicados desde 2000- los manuales que la encuadran de manera correcta entre 1609 y 1614. Relacionado con la fecha se encuentra el análisis geográfico. Desde ese punto de vista, se observa una clara tendencia a explicar el fenómeno tomando 
http://doi.org/10.15359/ree.25-3.21

http://www.una.ac.cr/educare

educare@una.ac.cr

como referencia el territorio valenciano. Se trata de una cuestión que, aunque no es incorrecta, sí refleja un análisis incompleto, puesto que soslaya la presencia de comunidades en otros territorios. En ese sentido, solo cabe destacar la aparición de menciones puntuales a Andalucía y las menos habituales aún a Murcia. Nada relativo a Castilla, donde, como se ha indicado, se concentró gran parte del problema morisco con posterioridad a 1571.

En el intento de analizar las causas que llevaron a Felipe III a decretar el destierro tienen peso las consideraciones de tipo religioso y social y el temor una invasión turco-berberisca. A ellas se añade el factor político, al que se presta mucha menos atención. Son muy pocos los manuales que logran cierto equilibrio al unir todas estas consideraciones. Por el contrario, es más habitual que se rescaten algunos de los tópicos ya vistos, en especial el relativo al peligro que suponía su prolificidad. Otro tanto ocurre cuando algunos textos vierten juicios de valor más deudores del arraigo de determinadas narrativas tradicional-nacionalistas y no tanto derivados de datos objetivos. Así ocurre cuando se afirma que la expulsión fue una medida muy celebrada o cuando se la califica de inoportuna o errónea.

Por lo demás, resulta sorprendente que haya manuales que no aporten datos numéricos, aunque sí se observa que la cifra de los 300000 individuos desterrados es aceptada por la mayoría. En ese sentido, solo se han detectado análisis más profundos en los documentos de trabajo que el Ministerio de Educación y Ciencia publicó en 1977 como guía para estudiantes de bachillerato a distancia. Influye en ello el hecho de que no se trata de un libro de texto al uso, sino de una guía para estudiantes a quienes, por su propia idiosincrasia, se les presupone, de entrada, una mayor madurez. También se ha observado que algunos manuales ofrecen datos por territorios, aunque no para todos. Sin embargo, se dice muy poco del destino de los sujetos expulsados. Cuando así ocurre, se generaliza al norte de África, obviando otros puntos que la historiografía ha dado por buenos en los últimos años.

El otro gran bloque de ideas sobre el que se apoyan las explicaciones de este tema es el relativo a las consecuencias del exilio. En este caso, la tónica general es incidir en los efectos negativos que conllevó, en el plano demográfico, la decisión de Felipe III. Así, el destierro sirve para explicar la crisis poblacional del XVII y se añade a otros factores como el impacto de las guerras, el aumento del clero o las epidemias. A ellos se añade de manera puntual la emigración a América. También se insiste en los efectos económicos. Se trata de un argumento especialmente visible en los manuales LGE, pero que siempre está presente en los textos publicados con posterioridad. En ellos se incide en el perjuicio que sufrió el sector agrícola, sobre todo en Aragón y Valencia.

Como ha quedado explicitado en el apartado de metodología, nuestro análisis no solo se ha circunscrito a los contenidos puramente historiográficos. El análisis de los hechos se completa en todos los manuales analizados con la presencia de imágenes, textos, mapas, líneas del 
http://doi.org/10.15359/ree.25-3.21

tiempo... En relación con ello, ha podido comprobarse que este tipo de herramientas constituye un complemento imprescindible a los contenidos teóricos y han sido estudiados desde muy diferentes puntos de vista por parte de la historiografía dedicada al análisis de textos escolares (Valls Montés, 1995, 1999).

Tabla 3: Empleo de recursos docentes relativos a las minorías socio-religiosas hispanas en los manuales escolares. España, 1973-2018. Frecuencia de repetición (por ley educativa)

\begin{tabular}{lrrrrrrrr}
\hline \multicolumn{1}{c}{ Recurso } & \multicolumn{2}{c}{ LGE } & \multicolumn{2}{c}{ LOGSE } & \multicolumn{2}{c}{ LOE } & \multicolumn{2}{c}{ LOMCE } \\
& $\mathbf{n}^{\circ}$ & $\%$ & $\mathbf{n}^{\circ}$ & $\%$ & $\mathbf{n}^{\circ}$ & $\%$ & $\mathbf{n}^{\circ}$ & $\%$ \\
\hline Cartografía & 8 & 20,5 & 2 & 18,2 & & & 1 & 5,3 \\
Textos & 21 & 53,8 & 4 & 36,3 & 1 & 16,7 & 8 & 42,1 \\
Imágenes & 6 & 15,4 & 2 & 18,2 & 4 & 66,6 & 2 & 10,5 \\
Esquemas & & & 1 & 9,1 & 1 & 16,7 & & \\
Cuadros estadísticos & 1 & 2,6 & & & & & 1 & 5,3 \\
Cronología & 2 & 5,1 & & & & & 2 & 10,5 \\
Gráficos & 1 & 2,6 & & & & & & \\
Vocabulario & & & 2 & 18,2 & & & 2 & 10,5 \\
Recursos web & & & & & & & 3 & 15,8 \\
\hline \multicolumn{1}{c}{ TOTALES } & 39 & 100 & 11 & 100 & 6 & 100 & 19 & 100 \\
\hline
\end{tabular}

Nota: Elaboración propia.

Al contrario de lo que se ha observado con los contenidos, estos materiales han experimentado un proceso de fosilización menor y han evolucionado de manera acorde con las nuevas metodologías docentes implantadas en los últimos años, aunque no siempre como cabría de esperar inicialmente (Gómez Carrasco y López Martínez, 2014). Desde ese prisma, parece clara la preferencia por el empleo de textos y cartografía, aunque, a medida que se avanza en el tiempo, se documenta una mayor diversificación en el empleo de materiales alternativos. Entre ellos, destacan las imágenes empleadas en un sentido más documental, a modo de complemento al contenido textual y no tanto con un carácter ilustrativo o meramente decorativo (Valls Montés, 2001).

Los datos confirman la variedad de este tipo de recursos. También la presencia de cambios y continuidades que conviene tener en cuenta. De hecho, hay recursos cuyo empleo se da de manera invariable a lo largo del tiempo e independientemente del marco legislativo. Entre 
http://doi.org/10.15359/ree.25-3.21

http://www.una.ac.cr/educare

educare@una.ac.cr

ellos, y de modo especialmente llamativo, los textos (bien históricos, bien historiográficos), las imágenes y los recursos cartográficos. De entre estos últimos, los relativos a la unificación territorial de la península ibérica durante la época de los Reyes Católicos son un buen ejemplo. Como lo es el recurso a la inclusión de textos seleccionados procedentes de la Historia de los Reyes Católicos de Andrés Bernáldez o la introducción casi sistemática de extractos de los bandos de expulsión de los judíos (1492) y de los moriscos valencianos (1609).

Figura 2: Empleo de recursos docentes relativos a las minorías socio-religiosas hispanas en los manuales escolares. España, 1973-2018. Tipología

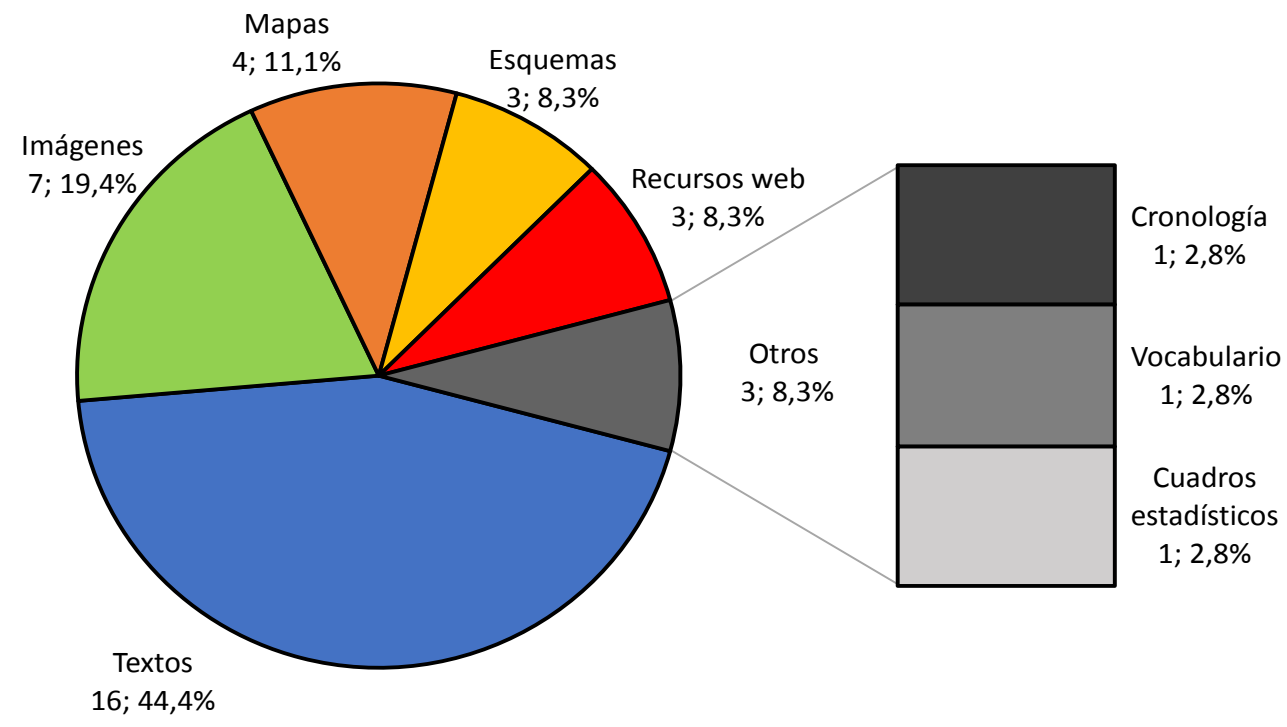

Nota: Elaboración propia.

Algo similar ocurre con las imágenes, donde sobresale el empleo de la denominada pintura de historia decimonónica, especialmente en los libros de las etapas LOE y LOGSE. Por su parte, en los manuales LGE se prefieren representaciones de época, datadas en los siglos XV a $\mathrm{XVII}$. En ese sentido, es recurrente el empleo de fotografías con los relieves de la capilla Real de Granada de Felipe Bigarny o del dibujo de Vicente Carducho sobre la expulsión de los moriscos, entre otros. En relación con el resto de recursos también hay variedad. Destaca el empleo de cuadros, cronologías y estadísticas de diverso tipo en los manuales LGE y LOMCE y de recursos web en la LOMCE, ausentes, por motivos obvios, en los textos anteriores. Su utilización supone un aliciente al trabajo autónomo del alumnado, puesto que permiten que el discente tome contacto con la interpretación televisiva, radiofónica, cinematográfica y virtual de la realidad estudiada en el aula por medio de los recursos clásicos. 


\section{Discusión}

La literatura escolar es el instrumento con el que los individuos de las sociedades occidentales se inician en el conocimiento de su pasado. Aunque la formación de la conciencia histórica también está condicionada por otros medios informales de conocimiento (Miralles Martínez y Gómez Carrasco, 2017), no cabe duda de que al libro de texto le corresponde un papel central en ese proceso. A pesar de los llamamientos a que las estrategias de aprendizaje se fundamenten en otros métodos pedagógicos y en la iniciativa personal del profesorado, lo cierto es que en España el día a día educativo ha estado determinado por la presencia de unos currículos muy rígidos. En ese contexto, los cuerpos docentes encuentran muchas limitaciones. Muchas vienen motivadas por la presión que suponen las pruebas de acceso a la universidad, cuya necesidad de superación implica el cumplimiento íntegro de los programas. Solo en los niveles no obligatorios de la educación secundaria ese margen parece mayor. Ni aun así, el profesorado queda exento de la obligación de cumplir con unos temarios encorsetados y a veces demasiado localistas. Este ultimo aspecto se ve acrecentado debido a la propia configuración político administrativa española, que facilita la intervención directa -e interesada- de los gobiernos regionales a la hora de dar forma a los currículos oficiales.

La redacción de este trabajo ha estado inspirada por la creencia de que es necesario conectar la práctica investigadora (que se realiza, fundamentalmente -pero no de forma exclusiva- en la universidad) con la transmisión de conocimientos al alumnado matriculado en las etapas formativas obligatorias, especialmente de enseñanzas medias. Para ello se ha tomado como base de análisis un caso particular (las minorías socio-religiosas ibéricas en la Edad Moderna), un marco geográfico muy concreto (España) y una etapa que también esta muy delimitada (el tardofranquismo, la Transición y la etapa democrática). El objetivo perseguido era averiguar si la enseñanza de ese tema había experimentado cambios como consecuencia de las transformaciones sociopolíticas y económicas del país y a resultas de las diferentes -y demasiado habituales- modificaciones de la normativa legal que rige el gobierno del sistema educativo en España.

Para profundizar en esas cuestiones se ha empleado un conjunto de manuales docentes cuya distribución crono-espacial aseguraba una visión panorámica del periodo y tema elegidos. El abordaje metodológico también se ha adaptado al objetivo perseguido y no solo se ha basado en el estudio puramente historiográfico de los contenidos, algo fundamental, por otra parte; también ha prestado atención al empleo de materiales e instrumentos de apoyo y a las siempre necesarias actividades que se proponen en cada manual para facilitar la recapitulación y la evaluación de contenidos.

El análisis que acaba con estas líneas ha permitido constatar que, a pesar de los cambios en la estructura y contenido de los currículos, las narrativas empleadas en los temas referidos a la Modernidad apenas si han experimentado cambios en el último medio siglo: Reyes Católicos, 
http://doi.org/10.15359/ree.25-3.21

http://www.una.ac.cr/educare

educare@una.ac.cr

empresa americana, España imperial y transformaciones borbónicas ocupan lo principal de un discurso que se ha abierto a cuestiones de orden socio-económico y cultural, pero que sigue siendo deudor de una orientación presentista y de una narración muy ligada a lo político (Molina et al., 2014). En ese contexto, nuestro trabajo ha permitido constatar que la historia de las minorías moriscas y de las judeoconversas ocupa un lugar aparentemente marginal, pero acorde con el peso general de los contenidos relativos a la propia época moderna. No hay, pues, un gran desfase, si bien es cierto, que las preguntas formuladas han permitido observar ciertas carencias, especialmente en lo relativo a la actualización de los contenidos impartidos.

De las minorías moriscas puede señalarse la toma en consideración de tres hitos que la historiografía siempre ha considerado claves: 1) las conversiones de los grupos musulmanes de Castilla (poco se dice de Aragón) que siguió a la conquista del emirato nazarí; 2) la rebelión de 1568-1570 en el propio reino de Granada; y 3) la expulsión decretada por Felipe III. Por desgracia, en el caso de los sujetos conversos el panorama es peor. La historia del pueblo judío, de su diáspora y de los descendientes de quienes optaron por convertirse al cristianismo apenas si va más allá del decreto promulgado por los Reyes Católicos en marzo de 1492. Cuando no ocurre así, las menciones a dicho colectivo siempre aparecen ligadas a la labor represora ejercida por la Inquisición. En ese sentido, las referencias al significado social de los conversos son pocas, suelen ir asociadas al fenómeno de la limpieza de sangre y, generalmente, van unidas a las leyes promulgadas de manera más reciente (LOE y LOMCE). Más allá de ello, nada.

Por su parte, el estudio de las actividades propuestas con carácter complementario y de los materiales docentes subsidiarios al contenido teórico de los manuales, tampoco ha experimentado grandes cambios, al menos por lo que se refiere al tema estudiado aquí. En ese sentido, es cierto que las propias LOE y LOMCE han asumido una mayor diversificación a la hora de presentar y hacer uso de esos recursos, pero no es menos verdad que los textos e imágenes (muchas veces repetidos desde antaño) siguen acaparando el grueso de esos recursos alternativos.

Lo anterior no significa que no haya habido avances. No cabe duda de que, en un periodo tan dilatado (casi medio siglo), se ha dejado sentir la paulatina incorporación de algunas de las aportaciones que la historiografía modernista ha afianzado desde el último cuarto del siglo XX. La toma en consideración de explicaciones multicausales, la observación de los problemas históricos analizados desde la perspectiva del otro ser y la incorporación de contenidos que van más allá de una mera explicación política del pasado son algunas de las principales novedades. El proceso está resultando lento, en parte por la rigidez de los programas oficiales, pero también debido a cuestiones de raíz sociopolítica y cultural (Gómez Carrasco, 2014), cuyo principal exponente es el mantenimiento interesado de las inercias narrativas de corte nacionalista tan opuestas a esa "nueva identidad ... plural e intercultural" (Pérez Garzón, 2008, p. 37) que debe contribuir a construir la historia. Muestra más que evidente de la triste desconexión que en España sigue existiendo entre la historia enseñada/aprendida y la historia investigada. 


\section{Declaración de Material complementario}

Este artículo tiene disponible, como material complementario:

-La versión preprint del artículo en https://doi.org/10.5281/zenodo.4042028

-Lista de manuales analizados en https://doi.org/10.15359/ree.25-3.21

\section{Referencias}

Amelang, J. S. (2011). Historias paralelas. Judeoconversos y moriscos en la España moderna. Akal.

Borre Johnsen, E. (1996). Libros de texto en el calidoscopio. Estudio crítico de la literatura y la investigación sobre los textos escolares. Pomares-Corredor.

Choppin, A. (1992). Les manuels scolaires: Historie et actualité. Hachette Education.

Domínguez Ortiz, A. (1978). Los judeoconversos en España y América. Istmo.

Domínguez Ortiz, A. (1997). El libro de texto en mis recuerdos. En L. Arranz Márquez (Coord.), Actas del V Congreso sobre el libro de texto y materiales didácticos (pp. 19-23). UCM.

Domínguez Ortiz, A. y Vincent, B. (1978). Historia de los moriscos. Vida y tragedia de una minoría. Revista de Occidente.

Fernández Palop, M. P. y Caballero García, P. A. (2017). El libro de texto como objeto de estudio y recurso didáctico para el aprendizaje: Fortalezas y debilidades. Revista Electrónica Interuniversitaria de Formación del Profesorado, 20(1), 201-217. https://doi.org/10.6018/ reifop/20.1.229641

Foster, S. (2011). Dominant traditions in international textbook research and revision. Education Inquiry, 2(1), 5-20. https://doi.org/10.3402/edui.v2i1.21959

García González, F., Gómez Carrasco, C. J. y Rodríguez Pérez, R. A. (Eds.). (2016). La edad moderna en educación secundaria. Experiencias de investigación. Editum.

Gómez Carrasco, C. J. (2014). Pensamiento histórico y contenidos disciplinares en los libros de texto. Un análisis exploratorio de la edad moderna en $2^{\circ}$ de la ESO. Ensayos. Revista de la Facultad de la Educación de Albacete, 29(1), 131-158. https://revista.uclm.es/index.php/ ensayos/issue/view/70

Gómez Carrasco, C. J., Cózar Gutiérrez, R. y Miralles Martínez, P. (2014). La enseñanza de la historia y el análisis de libros de texto. Construcción de identidades y desarrollo de competencias. Ensayos. Revista de la Facultad de la Educación de Albacete, 29(1), 1-25. https://revista.uclm. es/index.php/ensayos/article/view/532/447 
http://doi.org/10.15359/ree.25-3.21

http://www.una.ac.cr/educare

educare@una.ac.cr

Gómez Carrasco, C. J., García González, F. y Miralles Martínez, P. (Eds.) (2016). La edad moderna en educación secundaria. Propuestas y experiencias de innovación.

Gómez Carrasco, C. J. y López Martínez, A. M. (2014). Las imágenes de los libros de texto y su función en la enseñanza de la Historia. Diseño de un instrumento de análisis. Enseñanza de las Ciencias Sociales, (13), 17-29. https://www.raco.cat/index.php/EnsenanzaCS/issue/ view/21663

Gómez Carrasco, C. J. y Molina Puche, S. (2017). Narrativas nacionales y pensamiento histórico en los libros de texto de educación secundaria de España y Francia. Análisis a partir del tratamiento de los contenidos de la Edad Moderna. Vínculos de Historia, (6), 206-229. https://doi.org/10.18239/vdh.v0i6.276

Henarejos Carrillo, P. (2016). La edad moderna a través de la LOE y la LOMCE. En F. García González, C. J. Gómez Carrasco y R. A. Rodríguez Pérez (Eds.), La edad moderna en educación secundaria. Experiencias de investigación (pp. 141-153). Editum. https://www.academia. edu/25082227/La Edad Moderna en Educaci\%C3\%B3n Secundaria Experiencias de investigaci\%C3\%B3n

Jefatura del Estado (6 de agosto, 1970). Ley 12/1970, de 4 de agosto, por la que se concede un crédito extraordinario de 70.000 .000 de pesetas al Ministerio de Asuntos Exteriores para abonar cuotas de España de los años 1966 a 1969, ambos inclusive, al Fondo Especial de las Naciones Unidas. Boletín Oficial del Estado, Núm. 187, pp. 12525-1256. https://www. boe.es/boe/dias/1970/08/06/pdfs/A12525-12546.pdf

Jefatura del Estado (4 de octubre, 1990). Ley Orgánica 1/1990, de 3 de octubre, de Ordenación General del Sistema Educativo. Boletín Oficial del Estado, núm. 238, pp. 28927-28942. https://www.boe.es/eli/es/lo/1990/10/03/1

Jefatura del Estado (24 de diciembre, 2002). Ley Orgánica 10/2002, de 23 de diciembre, de Calidad de la Educación. Boletín Oficial del Estado, núm. 307, pp. 45188-45220. https:// www.boe.es/eli/es/lo/2002/12/23/10

Jefatura del Estado (4 de mayo, 2006). Ley Orgánica 2/2006, de 3 de mayo, de Educación. Boletín Oficial del Estado, núm. 106, pp. 17158-17207. https://www.boe.es/eli/es/lo/2006/05/03/2

Jefatura del Estado (10 de diciembre, 2013). Ley Orgánica 8/2013, de 9 de diciembre, para la mejora de la calidad educativa. Boletín Oficial del Estado, núm. 295, pp., 97858-97921. https://www.boe.es/eli/es/lo/2013/12/09/8

López Facal, R. (2010). Nacionalismos y europeísmos en los libros de texto. Identificación e identidad nacional. Clío \& Asociados. La historia enseñada, (14), 9-33. https://doi. org/10.14409/cya.v1i14.1673 
Martínez, N., Valls, R. y Pineda, F. (2009). El uso del libro de texto de historia de España en bachillerato: Diez años de estudio, 1993-2003 y dos reformas (LGE-LOGSE). Didáctica de las Ciencias Experimentales y Sociales, (23), 3-35. https://ojs.uv.es/index.php/dces/article/ view/2405/1950

Miralles Martínez, P. y Gómez Carrasco, C. J. (2017). Enseñanza de la historia, análisis de libros de texto y construcción de identidades colectivas. Historia y Memoria de la Educación, (6), 9-28. https://doi.org/10.5944/hme.6.2017.18745

Molina, S., Gómez, C. J. y Ortuño, J. (2014). History education under the new educational reformin Spain: New wine in old bottles? International Journal of Historical Learning Teaching and Research, 12(2), 122-132. https://doi.org/10.18546/HERJ.12.2.10

Pérez Garzón, J. S. (2008). ¿Por qué enseñamos geografía e historia? ¿Es tarea educativa la construcción de identidades? Historia de la Educación, 27, 37-55. http://campus.usal. es/ revistas trabajo/index.php/0212-0267/article/view/1596

Rodríguez Garrido, J. E. (2012). Trato y maltrato de la historia de España en los libros de texto de la EGB y la ESO [Tesis Doctoral]. Universidad Complutense de Madrid. https://eprints.ucm.es/ id/eprint/15236/

Valls Montés, R. (1995). Las imágenes en los manuales escolares españoles de historia, ¿ilustraciones o documentos? Íber. Didáctica de las Ciencias Sociales, Geografía e Historia, (4), 105-119.

Valls Montés, R. (1998). Recepción de los manuales de historia en los centros escolares españoles (siglos XIX y XX): Estado de la cuestión. Didáctica de las Ciencias Experimentales y Sociales, (12), 3-28. https://ojs.uv.es/index.php/dces/article/view/2940/2511

Valls Montés, R. (1999). Sobre la elección y usos de las imágenes de los manuales escolares de historia: Un ejemplo español (1900-1998). Clío y asociados. La historia enseñada, (4), 77100. https://bibliotecavirtual.unl.edu.ar/publicaciones/index.php/ClioyAsociados/article/ view/1547/2461

Valls Montés, R. (2001). Los estudios sobre los manuales escolares de historia y sus nuevas perspectivas. Didáctica de las Ciencias Experimentales y Sociales, (15), 25-36. https://ojs. uv.es/index.php/dces/article/view/2915/2487

Valls Montés, R. (2007). Historiografía escolar española: Siglos XIX-XXI. UNED.

Valls Montés, R. (2008). La enseñanza de la historia y textos escolares. Libros del Zorzal. 